\title{
Effectiveness of a primary care based multifactorial intervention to improve frailty parameters in the elderly: a randomised clinical trial: rationale and study design
}

Laura Romera ${ }^{1,2,3}$, Francesc Orfila ${ }^{3,4^{*}}$, Josep Maria Segura ${ }^{1,5}$, Anna Ramirez ${ }^{1}$, Mercedes Möller ${ }^{6}$, Maria Lluïsa Fabra ${ }^{6}$,

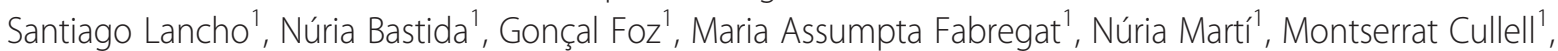
Dolors Martinez ${ }^{1}$, Maria Giné ${ }^{7}$, Anna Bistuer ${ }^{6}$, Patricia Cendrós ${ }^{8}$ and Elena Pérez ${ }^{9}$

\begin{abstract}
Background: Frailty is a highly prevalent condition in old age leading to vulnerability and greater risk of adverse health outcomes and disability. Detecting and tackling frailty at an early stage can prevent disability. The purpose of this study is to evaluate the effectiveness of a multifactorial intervention program to modify frailty parameters, muscle strength, and physical and cognitive performance in people aged 65 years or more. It also assesses changes from baseline in falls, hospitalizations, nutritional risk, disability, institutionalization, and home-care.

Methods/design: The current study is a randomised single-blind, parallel-group clinical trial, with a one and a half year follow-up, conducted in eight Primary Health Care Centres located in the city of Barcelona. Inclusion criteria are to be aged 65 years or older with positive frailty screening, timed get-up-and-go test between 10 to 30 seconds, and Cognition Mini-Exam (MEC-35) of Lobo greater than or equal to 18. A total of 352 patients have been equally divided into two groups: intervention and control. Sample size calculated to detect a 0.5 unit difference in the Short Physical Performance Battery (Common SD: 1.42, 20\% lost to follow-up). In the intervention group three different actions on frailty dimensions: rehabilitative therapy plus intake of hyperproteic nutritional shakes, memory workshop, and medication review are applied to sets of 16 patients. Participants in both intervention and control groups receive recommendations on nutrition, healthy lifestyles, and home risks.

Evaluations are blinded and conducted at 0, 3, and 18 months. Intention to treat analyses will be performed.

Multivariate analysis will be carried out to assess time changes of dependent variables.
\end{abstract}

Discussion: It is expected that this study will provide evidence of the effectiveness of a multidisciplinary intervention on delaying the progression from frailty to disability in the elderly. It will help improve the individual's quality of life and also reduce the rates of falls, hospital admissions, and institutionalizations, thus making the health care system more efficient. This preventive intervention can be adapted to diverse settings and be routinely included in Primary Care Centres as a Preventive Health Programme.

Trial registration: ClinicalTrials.gov PRS: NCT01969526. Date of registration: 10/21/2013.

Keywords: Frail elderly, Aged, Randomised controlled trial, Exercise, Disability, Primary health care, Treatment outcome

\footnotetext{
* Correspondence: forfila.bcn.ics@gencat.cat

${ }^{3}$ Institut Universitari d'Investigació en Atenció Primària Jordi Gol (IDIAP Jordi

Gol), Barcelona, Spain

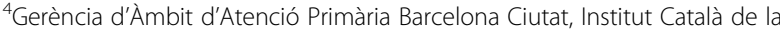

Salut, Barcelona, Spain

Full list of author information is available at the end of the article
}

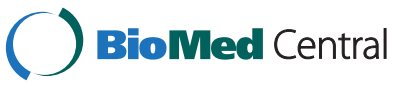

(C) 2014 Romera et al.; licensee BioMed Central Ltd. This is an Open Access article distributed under the terms of the Creative Commons Attribution License (http://creativecommons.org/licenses/by/4.0), which permits unrestricted use, distribution, and reproduction in any medium, provided the original work is properly credited. The Creative Commons Public Domain Dedication waiver (http://creativecommons.org/publicdomain/zero/1.0/) applies to the data made available in this article, unless otherwise stated. 


\section{Background}

The concept of frailty has long been associated with advancing age although only recently has it been specifically defined as a medical syndrome [1-4]. Disability, comorbidity, malnutrition, biological changes, cognitive impairment, dependency needs, and demands for social services are directly age-related; age, however, as an isolated criterion is not enough to identify vulnerability [5].

Despite considerable discussion, frailty remains to be systematically defined [6]. There is evidence that it increases proportionally to an accumulation of deficits [7]; acute problems -falls, fractures, and infections-, progressive loss of autonomy, and psychosocial limitations all lead to disability and a higher risk of hospitalization, institutionalization, and death $[8,9]$.

There is no agreement on a valid evaluation model for both research and clinical approaches [10], and some authors differentiate between physical and cognitive frailty [11]. The standard clinical proposal is that which has been presented by Fried et al. who identify someone as having a frail phenotype when three or more of the following components are presented [3]: unintentional weight loss $(4.5 \mathrm{~kg}(=10 \mathrm{lbs})$ in the past year), self-reported exhaustion (two positive questions of Center for Epidemiologic Studies Depression Scale (CES-D)), weakness, slow walking speed, and low levels of physical activity. Such a definition would be mainly related to physical frailty. For rapid frailty screening of a community-living elderly population these five criteria, however, do not represent a pragmatic approach [10]. Avila-Funes et al. proposed a review to slightly modify Fried's measurements in order to strengthen the predictive validity of the concept [12], with variable results $[13,14]$. In addition, Gill et al. introduced two tests of physical ability strongly associated with disability development and progression: the Rapid-Gait Test and the Stand-Up Test [15]. Other useful batteries of physical performance, such as the Short Physical Performance Battery (SPPB) from Guralnik, can also be found as predictors of old age disability [16,17].

Sarcopenia is linked to physical frailty and is a key feature of this condition in older people [18]. In fact, a non-negligible proportion of elderly individuals are moderately affected by this it [19]. Sarcopenia is related to loss of muscle mass and muscle strength, strong predictors of adverse health outcomes [20] and death [21,22].

Epidemiological studies have linked physical frailty and cognitive impairment: frailty increases the risk of cognitive decline and cognitive impairment increases the risk of frailty, therefore, both dimensions would benefit from being addressed [23,24].

Identifying interventions to prevent or delay the loss of autonomy is currently a public health priority for the successful management of the ageing [25,26]. Multidimensional home interventions have revealed some benefits, although conclusions are inconsistent and seem to be dependent on factors such as the provider's experience, access to monitoring, and duration of the follow-up program [15].

A comprehensive geriatric assessment, followed by a multidimensional intervention on disability risk factors -medical, functional, psychological, and environmental problems- through disease management and health promotion in a low-risk elderly population, succeeds in reducing institutionalization and the risk of falls, delaying disabled functional decline, and improving physical performance. The effects, however, are not statistically significant [27-29].

Strategies involving mass screening in Primary Care to apply preventive approaches based on healthy ageing advice, long-term exercise programs, assistance devices including home telecare kits [30], and environmental modifications can reduce falls [31]. Nevertheless, when considered separately, these methods have no impact on reducing disability [32].

Exercise programs improve strength, aerobic capacity, balance, and function [33,34], but these benefits depend on long-term adherence, extended training, and exerciserelated behaviours acquired in early life. The most promising strategies to increase physical activity in the elderly are those which provide appropriate written advice and generate feelings of fun and satisfaction [35].

Recent surveys have put forward new strategies for the management of sarcopenia to slow down the decline of muscle features: resistance training in combination with adequate protein and energy intake and, additionally, treatment of vitamin D deficiency [36,37].

Nutritional interventions alone show weak correlation with health improvement in the vulnerable, elderly population. However, dietary advice in association with protein supplementation intake seems to have some effects on sarcopenia, inducing muscle hypertrophy, accelerating weight gain in undernourished older people [38], and reducing fractures [39]. There is a lack of evidence, however, concerning its effects on mortality and hospital admission rates [40].

Findings from cognitive training studies show positive effects. Memory training can aid maintaining long-term improvement in performance [41,42].

Exercise also leads to enhanced cognitive functioning and psychological well-being in frail, older adults [43]. Aerobic exercise has shown effects on some measures of cognitive function, without consistency for all values [44].

There are few randomized, controlled trials concluding that cognitive interventions, plus complementary physical exercise, can produce significant global improvements in cognitive function, and quality of life, and delay the onset of disability [45].

What about medication use in frail, older adults? The rates of adverse drug events are higher in the elderly 
population, as many of them have comorbidities, multiple drug prescriptions, and deteriorated physical and cognitive impairment [46]. In the previous decade, deprescribing, based on clinical and ethical criteria, has been defended as an option for managing chronic conditions, avoiding adverse effects, and improving patient outcomes. Polypharmacy has been independently associated with an increase of mortality in the elderly [47], indeed, several multifaceted interventional studies have demonstrated that medication review has a positive effect on reducing mortality, hospital admissions and falls, and enhances quality of life [48].

Such a wide range of interrelated factors gives weight to our proposal to conduct a multifactorial intervention aimed at non-disabled, i.e. frail, elderly individuals. Our objective is to focus on this population whose health status still permits some positive modifications in the inevitable evolution from frailty to dependence so that by preventing home confinement or institutionalization, older people can stay active and live by themselves in the community.

\section{Study aim}

This is a research protocol for a randomized, controlled trial aimed at assessing the effectiveness of a multifactorial intervention program to modify parameters of frailty, muscle strength, and physical and cognitive performance in elderly people living in the community. The intervention includes various professional disciplines and is based on physical activity, diet supplementation, memory workshops, and medication review.

Secondary aims include evaluating changes in rates of falls fractures, hospital admissions, inclusions in home care programs, and institutionalizations.

\section{Methods/design Study design}

The study design is a single-blind, parallel-group, pragmatic, randomised, clinical trial with one year and a half follow-up.

Changes from baseline measurements (month 0) in the parameters of frailty, muscle strength, and physical and cognitive performance are compared between the intervention (IG) and control group (CG) at the end of the intervention (month 3). An 18 month follow-up after randomization will be established in order to determine whether intervention effects can be sustained. The 18 month changes in rates of falls, fractures, hospital admissions, inclusions in home care programs, institutionalizations and vital status will be analysed.

The CONSORT Statement extensions for trials of non-pharmacological interventions and pragmatic intervention trials were used to design the study and will be used to report it.

\section{Sample size calculation}

Sample size has been calculated to detect minimal significant effects on the variable of physical performance (SPPB): Accepting an alpha risk of 0.05 and a beta risk of 0.20 in a bilateral contrast, 318 individuals are required in order to detect a difference equal to or greater than 0.5 units in the SPPB $[49,50]$. The common standard deviation has been taken to be 1.42. A drop-out rate of $20 \%$ is anticipated. Finally, 352 subjects have been included ( $\mathrm{n}=176$ IG and $\mathrm{n}=176 \mathrm{CG}$ ).

\section{Ethical aspects}

Written informed consent has been obtained from all recruited subjects. Objectives, tests and other details about methodology and interventions were explained orally and in writing. The trial was approved by the Ethics Committee of the IDIAP Jordi Gol (code number P12/047) on June 1st, 2012. Funding from the Carlos III Health Institute was granted on December 20, 2012 (project code PI12/01503).

\section{Participants and recruitment}

From February 2013 to January 2014, 370 individuals aged 65 years and over were recruited from 8 Primary Healthcare Centres (PHCC) located in two different districts of Barcelona. A total population of 33,857 aged 65 years and over live in the reference area.

Subjects were recruited by referral from the PHCC where the opportunity to participate in the study was offered on a regular daily basis to all patients meeting preliminary frailty criteria (Barber Questionnaire [51]). Eligibility was then verified with an assessment by a Case Management Nurse (CMN) through a personal interview. Participants meeting at least 3 Fried modified frailty criteria were included whilst those individuals with very slow or rapid gait speed, or cognitive impairment based on MEC35 of Lobo [52], were excluded.

Inclusion and exclusion criteria are shown in Table 1.

The flow-chart of the trial according to CONSORT 2010 is visualized in Figure 1.

Eligible patients who agreed to participate in the study were invited to sign the informed consent. Baseline variable collection was carried out by the CMN. Patients were then randomly assigned to the intervention and control groups. The computer-assisted simple randomization process was performed not by the recruiters but by an independent researcher. Random allocation sequence was implemented using sequentially numbered containers. Sequence was concealed until the interventions were assigned. Baseline and outcome measurements were blinded to group assignment. Follow-up evaluations are conducted by blind trained clinical researchers. 
Table 1 Inclusion and exclusion criteria

\begin{tabular}{|c|c|}
\hline Inclusion criteria & Exclusion criteria \\
\hline - 65 years or older & \multirow{4}{*}{$\begin{array}{l}\text { - Medical conditions such as the presence of: unstable angina, uncontrolled } \\
\text { congestive heart failure, unstable arrhythmia, COPD stage III or IV which } \\
\text { contraindicate following a program of physical activity }\end{array}$} \\
\hline - Resident in Barcelona, community-dwelling & \\
\hline \multirow{2}{*}{$\begin{array}{l}\text { - Assigned to one of the } 8 \text { PHCC } \\
\text { - Can attend on-site the consultation room at the PHCC }\end{array}$} & \\
\hline & \\
\hline - Will stay in the reference area a minimum of one year and a half & $\begin{array}{l}\text { - Home Care Program or institutionalization at baseline. Planned admission to } \\
\text { nursing home }\end{array}$ \\
\hline • Frailty inclusion criteria: & - Participation in other physical activity program \\
\hline - score of 1 point or above in the Barber Questionnaire & \multirow{2}{*}{$\begin{array}{l}\text { - Has been operated on hip and/or knee the last } 6 \text { month (walking } \\
\text { independently with technical assistance is not a contraindication) }\end{array}$} \\
\hline - Fried modified frailty criteria: 3 or more & \\
\hline - Gait time between 10 to 30 seconds in the Timed Get Up and Go test & - Suffering a non-controlled neoplastic disease, terminal or severe disabling illness \\
\hline - MEC-35 of Lobo $\geq 18$ points (no severe cognitive impairment) & - Cannot understand Spanish \\
\hline Capable of consent. Agreement to participate in the study & \\
\hline
\end{tabular}

\section{Measures}

Both cohorts receive identical baseline and follow-up evaluations. Table 2 shows the different time points when variables are measured.

1. Fried modified criteria for frailty [3] (three or more of the following criteria have to be present):

- Unintentional weight loss (3 kg in past 6 months)

- Self-reported exhaustion (2 questions from CES-D scale)

- Weakness (5 chair stand-up test, unable)

- Slow walking speed (more than 10 seconds) evaluated by Timed -up-and-Go test (TGUGT). This is a reliable test for quantifying functional mobility (lower extremities function) and for measuring balance (fall risk). The person may wear their usual footwear and can use any assistive device normally employed. The TGUGT is conducted using a chair with arms, and a seat height of $46 \mathrm{~cm}$, placed upon a flat surface with a line marking the $3 \mathrm{~m}$ turning point. Subjects are instructed on the word 'go', to get up and walk as quickly and as safely as possible to cross the line marked on the path, turn around, walk back to the chair and sit down again. The activity will be timed from the subject's back leaving the back of the chair to the return of the subject to this same position.

- Low physical activity measured by the IPAQ Questionnaire [53].

2. Physical performance:

\subsection{Short Physical Performance Battery.}

The short physical performance battery (SPPB) is a simple standardised objective assessment tool of lower limb function [16] that tests standing balance, ability to repeatedly stand from a sitting position, and habitual gait speed. Each component is scored between 0-4 (total score 0-12) with higher scores indicating better functioning. In community-dwelling older adults, lower SPPB scores predict greater risk of mortality, nursing home admission, hospitalization, and incidence of disability. The SPPB consists of:

\subsection{1) Balance test}

Participants are asked to hold three increasingly challenging standing positions for 10 seconds each: (1) a side-by-side position, (2) semi-tandem position (the heel of one foot beside the big toe of the other foot), (3) tandem position (the heel of one foot in front of and touching the toes of the other foot).

\subsection{2) Repeated chair stands test}

This is performed using a straight-backed chair, placed with its back against a wall. Participants are first asked to stand from a sitting position without using their arms. If they are able to perform the task, they are then asked to stand up and sit down five times, as quickly as possible, with arms folded across their chest. The time to complete five stands is recorded and used for future analyses.

\subsection{3) Gait speed (8 meters walk)}

This test is adapted from the 2.4 meter (8 feet) walking test in the SPPB, and use of an assistive device (e.g., cane or walker) is allowed. Participants are asked to walk 8 meters distance at their usual pace from a standing position; timing begins when the patient is told "go" and crosses the first line and ends when the 8 meter mark is crossed. There is a total distance of 12 meters (two 


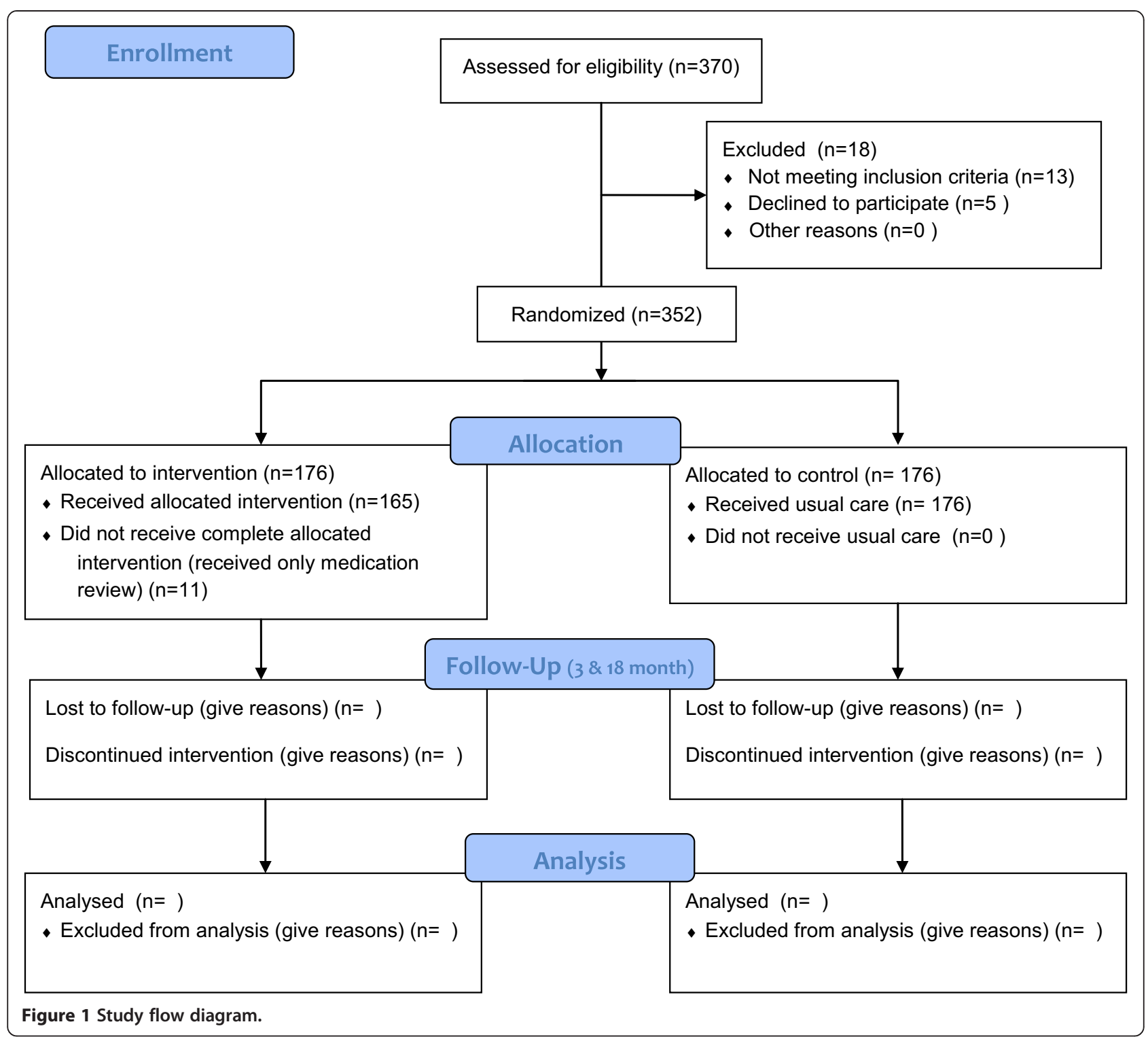

meters on each side of the marks to allow for acceleration and deceleration). Participants then have to complete the same practice walking as fast as they are comfortably able to do so. Raw scores are recorded in seconds required to walk 8 meters on each of the two trials.

\subsection{Functional Reach Test (FRT).}

This is a valuable test used to measure standing balance and stretching, detecting balance impairment over time. It can predict the risk of falling. After the examiner explains and shows the FRT, each subject performs 2 trial tests. Functional reach is measured by using a levelled yardstick attached to the wall at the height of the subject's right acromion. To measure the subject's reaching distance, an examiner stands $0,5 \mathrm{~m}$ away from the measuring tape and records the end reach position, checking that the initial position is correct: subjects stand comfortably with feet approximately shoulder-width apart, just before a line marked on the floor at the same level as the measuring tape beginning $(0 \mathrm{~cm})$; participants then extend the right arm parallel to the yardstick and, without touching the wall, place the third metacarpal along the measuring tape and have to reach as far forward as they can without losing their balance (end position). Subjects are allowed to balance on their toes; however, touching the wall, stepping while reaching forward, or holding onto their clothing with the left hand invalidate the trial. If invalidated, the trial is 
Table 2 Measurements at several time points

\begin{tabular}{|c|c|c|c|c|c|c|c|}
\hline & \multirow{2}{*}{$\begin{array}{c}\text { Selection } \\
\text { All }\end{array}$} & \multicolumn{2}{|c|}{ Baseline } & \multicolumn{2}{|c|}{ After intervention } & \multicolumn{2}{|c|}{18 months } \\
\hline & & IG & $\overline{C G}$ & IG & CG & IG & CG \\
\hline \multicolumn{8}{|l|}{ FRAILTY MEASURES } \\
\hline Barber Questionnaire & $x$ & & & & & & \\
\hline Fried modified criteria & $x$ & & & & & $x$ & $x$ \\
\hline SPPB & & $x$ & $x$ & $x$ & $x$ & $x$ & $x$ \\
\hline FRT & & $x$ & $x$ & $x$ & $x$ & $x$ & $x$ \\
\hline Unipodal Station & & $x$ & $x$ & $x$ & $x$ & $x$ & $x$ \\
\hline Strength of upper extremities & & $x$ & $x$ & $x$ & $x$ & $x$ & $x$ \\
\hline Strength of lower extremities & & $x$ & $x$ & $x$ & $x$ & $x$ & $x$ \\
\hline \multicolumn{8}{|l|}{ FUNCTIONAL ASSESSMENT } \\
\hline Lawton \& Brody Scale & & $x$ & $x$ & & & $x$ & $x$ \\
\hline Barthel Index & & $x$ & $x$ & & & $x$ & $x$ \\
\hline \multicolumn{8}{|l|}{ NUTRITION } \\
\hline MNA & & $x$ & $x$ & & & $x$ & $x$ \\
\hline \multicolumn{8}{|l|}{ COGNITIVE EVALUATION } \\
\hline MEC-35 of Lobo & $x$ & & & & & & \\
\hline Short and Medium-Term Verbal Memory & & $x$ & $x$ & $x$ & $x$ & $x$ & $x$ \\
\hline Animal Naming Test & & $x$ & $x$ & $x$ & $x$ & $x$ & $x$ \\
\hline Evocation of words & & $x$ & $x$ & $x$ & $x$ & $x$ & $x$ \\
\hline Designation of famous people names & & $x$ & $x$ & $x$ & $x$ & $x$ & $x$ \\
\hline Verbal designation of images & & $x$ & $x$ & $x$ & $x$ & $x$ & $x$ \\
\hline Verbal abstraction of word pairs & & $x$ & $x$ & $x$ & $x$ & $x$ & $x$ \\
\hline \multicolumn{8}{|l|}{ DRUGS and PRESCRIPTION } \\
\hline Total number of drugs & & $x$ & $x$ & $x$ & $x$ & $x$ & $x$ \\
\hline Psychotropic Medication presence & & $x$ & $x$ & $x$ & $x$ & $x$ & $x$ \\
\hline Withdrawal of drugs & & & & $x$ & $x$ & $x$ & $x$ \\
\hline \multicolumn{8}{|l|}{ OTHER VARIABLES } \\
\hline Comorbidities & & $x$ & $x$ & & & $x$ & $x$ \\
\hline Biological measurements & & $x$ & $x$ & & & $x$ & $x$ \\
\hline Analytical parameters & & $x$ & $x$ & & & $x$ & $x$ \\
\hline Sphincter incontinence & & $x$ & $x$ & & & $x$ & $x$ \\
\hline Visual impairment & & $x$ & $x$ & & & $x$ & $x$ \\
\hline Auditive impairment & & $x$ & $x$ & & & $x$ & $x$ \\
\hline Technical support aids & & $x$ & $x$ & & & $x$ & $x$ \\
\hline Quality of Life: SF12 & & $x$ & $x$ & & & $x$ & $x$ \\
\hline \multicolumn{8}{|l|}{ ADVERSE OUTCOMES } \\
\hline Falls & & $x$ & $x$ & & & $x$ & $x$ \\
\hline Fractures & & $x$ & $x$ & & & $x$ & $x$ \\
\hline Hospital admissions & & $x$ & $x$ & & & $x$ & $x$ \\
\hline Home care inclusions & & & & & & $x$ & $x$ \\
\hline Institutionalizations & & & & & & $x$ & $x$ \\
\hline Death & & & & & & $x$ & $x$ \\
\hline
\end{tabular}


repeated with a maximum of 2 tests more to achieve 2 valid trials. All subjects are protected during the test. The best result from the two attempts is recorded.

\subsection{Unipodal station}

The patient is placed in a standing position, arms crossed over the chest, with one leg used for support in an extended position, and the other slightly bent at the knee (there can be no contact between the two legs). Once placed in the correct position (eyes open), the chronometer is activated and then stopped when either the patient moves the foot used as a base or when 30 seconds have passed; two attempts with the same foot are made and the best result recorded.

3. Muscle strength.

3.1 Evaluation of upper extremities strength is assessed through the measurement of force with a handgrip dynamometer. Grip strength is assessed using a portable hand dynamometer (JAMAR ${ }^{\circ}$ $90 \mathrm{~kg}$, coding 506320). The participants are seated with their shoulder in a neutral position and their elbow flexed at $90^{\circ}$. Three attempts are performed alternately in each hand; the mean of the three measures is recorded.

3.2 Evaluation of lower extremities strength is assessed through the bilateral measurement of the quadriceps muscle force using a digital dynamometer (Chronojump 1.4.5-1.4.6 Boscosystem ${ }^{\oplus}$ Encoder).

4. Activities of Daily Living (ADL) assessment:

4.1 Lawton $\mathcal{E}$ Brody Instrumental Activities of Daily Living scale [54].

This is an instrument assessing independent living skills which are considered more complex than the basic activities of daily living. The instrument is most useful for identifying how a person is functioning at the present and for observing improvement or deterioration over time. There are 8 domains of function measured with the Lawton \& Brody scale. Women have been traditionally assessed in all 8 areas of function whilst men have not been asked about the domains of food preparation, housekeeping, and laundering. Individuals are scored according to their highest level of functioning in that category. A summary score ranges from 0 (low function, dependent) to 8 (high function, independent).

4.2 Barthel Index of Basic Activities of Daily Living [55]. First developed in 1965, it measures functional disability by quantifying patient performance in 10 activities of daily life. These activities can be grouped according to self-care (feeding, grooming, bathing, dressing, bowel and bladder care, and toilet use) and mobility (ambulation, transfers, and stair climbing). 5-point increments are used in scoring, with a maximal score of 100 indicating that a patient is fully independent in physical functioning, and a lowest score of 0 representing a totally dependent bed-ridden state.

5. Nutritional Assessment:

Mini Nutritional Assessment MNA ${ }^{\oplus}$ [56]. The MNA consists of four parts: anthropometric

measurements, general status, diet information, and subjective assessment. A score of less than 17 points (out of a maximum of 30 ) is regarded as an indication of malnutrition, $17-23.5$ points indicate a risk of malnutrition and $>23.5$ points indicate that the person is well nourished.

6. Neuropsychologist Performance:

The first neuro-psychometric instrument developed in Spain to measure semi-quantitatively cognitive status in clinical neurology was the Barcelona Test (BT). A shortened version of the BT, named Barcelona Test Review [57], is used for neuropsychological area evaluation in our participants and it takes only 20-30 minutes to administer. Tests applied are:

6.1. Short and Medium-Term Verbal Memory is the capacity to hold a small amount of information in the mind in an active, readily available state for a short period of time (seconds) and medium-term period of time (minutes). For the condition referred to as short term, subjects will be instructed to listen to a little story text, 21-pieced-sentences (elements), read by a blind evaluator; once finished, the patient will be asked to repeat the general content and as many details as he or she can remember; the duration of short-term memory is believed to be in the order of seconds. Then, the participant will be submitted to other cognitive trials to divert attention. After 25 minutes, the subject is directly asked for the story again to evaluate medium-term verbal memory. A commonly cited capacity of short and medium-term is $7 \pm 2$ elements.

6.2. Animal Naming Test consists of asking the patient to name as many animals as possible in one minute. A blind evaluator must write down the answers, so they can be checked for duplicate responses (repeated words invalidate one of them). The goal of this test is to score at least 14 .

6.3. Evocation of words beginning with one explicit letter, similar to the previous test, in this case the participant will tell the examiner as many words beginning with "p" as possible in three minutes (repeated words invalidate one of them). All kinds 
of words are allowed, except plurals or the masculine and feminine of the same word, conjugating verbs, and diminutives. The goal of this test is to score at least 27.

6.4. Designation of famous people names, the identification of 30 famous faces and their corresponding name permits an examination of the semantic brain area and can identify a possible clinical syndrome of prosopagnosia. Evaluated by "success", "failure" or "tip of the tongue (TOT) phenomenon", goal is 23 success, 3 failure, 4 TOT.

6.5. Verbal designation of images. Fourteen pictures of different objects or animals are presented to participants and they have to identify each name as quickly as they can: if subjects guess the name between $0-3$ seconds this signifies 3 points, between $3-10$ seconds, 2 points, and if takes 10-30 seconds it represents 1 point. If the patient does not recognize the picture-name, it is equivalent to 0 points. Goal of the test is to score 41 points.

6.6. Verbal abstraction of word pairs, also called "Similarities - Abstraction", explores patients' concept formation ability, as the participant must "extract" the common abstract element that links the two words featured. Through this test the ability to discriminate "concrete thinking "from" abstract thought" can be evaluated. The goal of this test is to score at least 5 of 6 pair of words.

7. Medication

7.1. Number of prescribed drugs.

7.2. Number of prescribed benzodiazepines.

7.3. Presence of antidepressants (yes/no).

7.4. Withdrawal of drugs (yes/no).

7.5. Number of drugs retired at the closing date of the study.

8. Quality of life. 12-Item Short-Form Health Survey (SF-12) [58].

9. Adverse Outcomes: Falls, fractures, hospital admissions, institutionalization, inclusion in a Home-Care Program, or death.

\section{Independent variables}

Age. Gender. Marital status. Cohabitation. Education Level. Socioeconomic status. Existence of elevator in the building. Provision of regular company.

- Co-morbidities assessed in the clinical record: osteoarthritis, fractures in the last 5 years (hip fracture specified), presence of prosthetic joints, vision impairment, hearing impairment, cardiovascular diseases (hypertension, stroke, ischemic heart disease, arrhythmia, congestive heart failure, intermittent claudication, chronic venous insufficiency), pulmonary diseases (Chronic
Obstructive Pulmonary Disease (COPD), asthma), endocrinology diseases (diabetes, dyslipidemia, obesity, hypothyroidism, hyperthyroidsim), hematological (anemia), neurologic (Parkinson's disease), psychiatric (anxiety, depression), chronic kidney disease.

- Comorbidity measured with Charlson Index [59].

- Biological variables: weight, height, body mass index, waist circumference, blood pressure.

- Analytical variables: hemoglobin, serum lipid profile, serum protein, serum albumin, glomerular filtration rate, plasma creatinine, glycated hemoglobin, ferritin, iron, vitamin D, vitamin B12, folic acid.

- Incontinence (urinary, fecal, both).

- Urinary catheter (yes/no).

- Wearing a diaper (yes/no).

- Usual sensation of light-headedness.

- Smoking (non-smoker, ex-smoker, current smoker).

- Devices for mobility (cane, walker).

- Falls, fractures, and hospitalizations in the previous year.

\section{Intervention}

The intervention consists of a triple disability preventive therapy, consecutively applied to each subject in the intervention group, in groups of 16 participants (see Table 3):

1) Rehabilitation therapy plus the posterior intake of 1 hyperproteic nutritional shake which is then taken daily for 1 month. All patients in the intervention group perform the aerobics exercise plan in the primary care centre, 60-minute session twice a week on non-consecutive days for 6 weeks (12 sessions of 60 minutes each). Subjects must incorporate a progressive increase in the intensity of the exercise in each session. One session a week is dedicated to work with balance and the other to strength training. Both balance and strength are based on functional exercises. All sessions begin with a warm up for 5 minutes, and end by cooling off for another 5 minutes with relaxing exercises. The sessions are conducted under the supervision of a specialist in physical activity. A hyperproteic nutritional shake is provided at the end of each session, and the amount of shakes needed for one month's consumption post-physical therapy is assigned. The safety of the exercise program is measured by reviewing the record sheet for each patient in the training program, ascertaining cardiovascular decompensation and musculoskeletal injuries.

2) Memory workshops. Two speech therapists from the rehabilitation unit conduct 12 sessions of practical exercises (written, oral, corporal, and musical) in groups of 16 participants. Each of the 12 
Table 3 Description of Interventions

\subsection{Description of the rehabilitation therapy}

\section{Basic exercise}

- Chest Press against elastic resistance - sitting on a chair

- Reverse Butterfly against elastic resistance - sitting on a chair

- Arm press against elastic resistance - sitting on a chair

- Stand up with palms on thighs sitting on a chair

- Lift the legs with hands on hips sitting on a chair

- Hip abduction/adduction - sitting on a chair

- Knee flexion - sitting on a chair

- Knee extension - sitting on a chair

- Heel raises - sitting on a chair

\section{Alternative exercise}

\section{- Chest Press against the wall}

Muscle group

- Pectoral muscles

- Upper back muscles
- Arm press against elastic resistance - standing position

- Stand up using hand weighs - sitting on a chair

- Hip abduction/adduction - standing position

- Knee flexion - standing position
- Muscles of the arms, and shoulders

- Quadricep, hamstring, and gluteal muscles

- Hip flexor muscles

- Abductor/Adductor muscles

- Hamstring muscles

-Quadricep muscles

- Gastrocnemius and soleus muscles

3.2 Description of the memory workshops

Memory

Short and Long-Term Visual

Memory

Short and Long-Term Written

Memory

Short and Long-Term Oral Memory

Short and Long-Term Musical

Memory

Working memory: identification of hidden figures test

Memorize an image and draw it from memory

True/False sentences

Logos recognition

Geographical memory practice
Language

Evocation of words beginning with different letters

Crosswords

Completeness of unfinished sentences

Oral communication with clue words

Word search

Synonyms and antonyms

Matching words and their meaning

Visual-verb generation task: denomination of images, objects, parts of the human body

Rearrange letters to form a word and rearrange words to form grammatical sentences
3.3 Description of the polymedication review

Who does the intervention?

What are the objectives and criteria?

\footnotetext{
To reduce drug prescription of polymedicated patients* if possible,
following:

Depending on the baseline drug prescription at the beginning of the

Depending on the baseline drug prescri
study.
To reduce drug prescription of polymedicated patients* if possible,
following:
-Stopp criteria,

Sensory activation

Series of logical visual pattern recognition

Marking edge of silhouettes

Coloring components of Hidden Figures Test

Spot the differences between two pictures

Picture copies execution

Objects, materials and sounds recognition with closed eyes

Group interaction by singing and musical performances

Famous faces recognition
Reasoning and calculation

Gnosia and praxia different developing techniques (reproduction of pragmatic models)

Letters and numbers matching through Maze Paths

Executive functions enhancing: abstract concepts of similar but different objects

Identification of the inappropriate word in a pool of words

Reading and exclusion of senseless sentences

Filling the gap

Numerical skills practice: operations and mental agility
2 doctors from the Project Group.

\section{How is the intervention performed?}

A personalized e-mail is sent to each GP responsible for the patient participating in the intervention group throughout the first week of patient inclusion.

Every e-mail considers the individual profile of the patient referred and tries to adapt the general criteria to each particular case. 
sessions lasts 90 minutes and is conducted twice a week. Each person in the intervention group has their own material to work short and long-term memory, with exercises for the identification of figures and images, evocation of words, true or false sentences, crosswords, completion of unfinished sentences, and other language exercises such as synonyms and antonyms.

3) Medication Review. Reduction of potentially inappropriate medications, especially in polymedicated patients, after review from general practitioners. A patient is considered to be polymedicated when taking more than five medications daily and continuously for a period not less than six months. Medication review follows the Screening Tool of Older Persons' potentially inappropriate Prescriptions (STOPP) criteria [60]. In addition to the review of medication, verbal guidance on each of the drugs consumed is also provided. After an e-mail sent with the changes suggested by two doctors from the Project Group, this intervention is carried out by every patient's general practitioner, during the first month of the intervention, in a maximum of 3 clinical interviews for that purpose. It especially focuses on reducing the consumption of benzodiazepines or other psychotropic drugs.

The intervention group also receives two group sessions regarding dietary advice, lifestyles, and home hazards.

\section{Control group}

Subjects in the control group continue with their daily activities and receive regular monitoring and treatment of their diseases by their general practitioners. They are also invited to two group sessions regarding dietary advice, lifestyles, and home hazards.

\section{Statistics}

Intention to treat analyses will be performed. Baseline characteristics will be compared between groups by independent $\mathrm{t}$ tests and Chi-square tests. Outcome variables will be calculated for each individual and time point (difference between the result of SPPB, muscle strength, and other frailty variables in each time point and the initial value), and 95\% confidence intervals for the differences between groups will be calculated. Data will be analysed using repeated measures analysis of variance (ANOVA) consisting of intervention and control groups and time (baseline, post-intervention, follow-up).

Also, for longitudinal adverse outcome measures (disability, home care inclusion, institutionalization or death), survival analyses using Cox's regression models will be applied. The statistical significance level will be set at $\mathrm{p}<0.05$.

\section{Discussion}

Our study is addressed at evaluating the effectiveness of a multifactorial intervention to improve frailty parameters and prevent disability in patients 65 years or older. Improvements in physical performance, muscle strength, nutritional status, and cognitive performance are expected, as well as a reduction in the incidence of new complications such as falls, fractures, hospital admissions, and worsening of ADL scales, all of which are related to the appearance of disability $[33,34]$. Tackling frailty in a multifaceted manner will also diminish adverse outcomes such as inclusion in a home-care program, institutionalization or death.

In the field of preventive geriatrics, studies have shown that exercise training has clinical benefits inducing positive physiologic changes in muscle and function while multinutrient supplementation alone, without concomitant exercise, does not reduce muscle weakness or physical frailty [61].

The innovation of our study lies in regard to the followup and evaluation of a multifaceted strategy focused on different risk factors: physical decline, cognitive impairment, nutritional status, and polypharmacy. Previous series have provided a certain degree of evidence about improvement with these interventions on only an individual basis.

The greatest limitation of this study could proceed from the lack of agreement in the scientific community 
with respect to the definition of frailty and the most suitable measurements to gauge it. Including non- frail subjects (non-homogeneous risk state) could affect generalizability. The initial inclusion criterion, the low specificity Barber Questionnaire, has been included in this study because it was the first frailty test to be used in our clinical records. It has been also complemented, however, with other inclusion criteria such as the TGUGT. Participants scoring lower than 10 seconds or higher than 30 are excluded as they are considered either too frail or not frail enough to benefit from the intervention. The exclusion of more severely affected frail patients, because of their poor physical or cognitive condition, may limit external validity. Nevertheless, the random distribution of our patients to both groups guarantees comparability. Also, additional information about potential confounders (comorbidity, sensory impairment, and social risk) and the use of other parameters and tests of frailty are expected to solve the possible selection bias and help to further characterize the study population. Losses to follow-up are minimized through contacting the participants by telephone.

If evidence of a multi-strategy composed of physical exercise and a cognitive workshop, along with nutritional support and medication review, is achieved as an effective approach, a future implementation should be considered as a Frail-Community Prevention Program for the elderly to prevent or delay disability.

\section{Abbreviations \\ MEC-35: Cognition Mini-Exam of Lobo; SD: Standard deviation; CES-D: Center for Epidemiologic Studies Depression Scale; SPPB: Short Physical Performance Battery; IG: Intervention group; CG: Control group; CONSORT: Consolidated standards of reporting trials; PHCC: Primary Health Care Centre; CMN: Case Management Nurse; TGUGT: Timed get up and go test; FRT: Functional reach test; ADL: Activities of daily living; MNA: Mini Nutritional Assessment; BT: Barcelona Test; SF-12: 12-Item Short-Form Health Survey; COPD: Chronic obstructive pulmonary disease; STOPP: Screening Tool of Older Persons' potentially inappropriate Prescriptions. \\ Competing interests \\ The authors declare that they have no competing interests. \\ Authors' contributions \\ Conception of the idea for the study: AR, JMS, LR and FO. Development of the protocol, organization and funding: LR, JMS and FO. All authors contributed to the study design and development of the trial protocol. Writing of the manuscript: LR, FO, JMS, GF. All the authors read the draft critically to make contributions and approved the final manuscript.}

\footnotetext{
Acknowledgments

The authors gratefully acknowledge to all the professionals participating in the "Fragility Study" and all those who were involved and are no longer with us, Guillem Cifré. Special thanks to the staff and participants of the eight Primary Healthcare Centres of the Institut Català de la Salut, all them located in Barcelona. We would like to thank the Primary Heathcare Research Institution IDIAP Jordi Gol for it collaboration. We also thank Xavier de Blas for his infinite patience and support about the Chronojump Encoder. The authors owe much gratitude to the special contribution of the following collaborators, without whom this project would not have been possible: Maria-Milagros Guerrero, Sonia Martínez, Carmen López, Maria José Riazuelo, Neu Aizcorbe, Laura-Isabel Pérez and Mario Martin (Raval Sud Primary Health Centre), Patricia Furió (Casc Antic Primary Health Centre), Ana Muñoz (Poble Sec and Universitat Primary Health Centres), M Teresa Isidro (Avinguda Roma
}

Primary Health Centre), Nuria Lladró (Sant Antoni Primary Health Centre), Hèlia Marta Cebrian (Gotic Primary Health Centre), Agnés Salvador, David Garcia, Lucía López, Francesc Torres, Núria Bernaus, Ferran Povedano (Raval Nord Primary Health Centre) and Núria Duch (Manso Primary Health Centre). We also thank Nestlé Health Science for supplying nutritional shakes.

\section{Sources of funding}

A major funding was received from the Carlos III Health Institute of the Ministry of Health of Spain (FIS:PI12/01503) for the main development of the trial protocol. Also from the Fundació Mutuam Conviure, Becas Esteve de Innovación en Salud 2013 and the VIII Primary Health Care Research Award from Regió Sanitària de Barcelona. Dr Romera has a PhD research grant from IDIAP Jordi Gol.

\section{Author details}

${ }^{1}$ Primary healthcare centre Raval Nord, Institut Català de la Salut, Barcelona, Spain. ${ }^{2}$ Universitat Autònoma de Barcelona, 08193 Bellaterra, Spain. ${ }^{3}$ Institut Universitari d'Investigació en Atenció Primària Jordi Gol (IDIAP Jordi Gol), Barcelona, Spain. ${ }^{4}$ Gerència d'Àmbit d'Atenció Primària Barcelona Ciutat, Institut Català de la Salut, Barcelona, Spain. ${ }^{5}$ Department of Medicine, Universitat de Barcelona, Barcelona, Spain. ${ }^{6}$ Rehabilitation Unit, Drassanes Health Centre, Institut Català de la Salut, Barcelona, Spain. ${ }^{7}$ Department of Physical Activity and Sport Sciences, FPCEE Blanquerna, Universitat Ramon Llull, Barcelona, Spain. ${ }^{8}$ Social Training Centre Mil.lenari, Universitat Oberta de Catalunya, Vic, Spain. ${ }^{9}$ Family and Social Welfare, Institut Català d'Assistència I Serveis Socials (ICASS), Barcelona, Spain.

Received: 6 October 2014 Accepted: 13 November 2014 Published: 27 November 2014

\section{References}

1. Bergman H, Ferrucci L, Guralnik J, Hogan DB, Hummel S, Karunananthan S, Wolfson C: Frailty: an emerging research and clinical paradigm-issues and controversies. J Gerontol A Biol Sci Med Sci 2007, 62:731-737.

2. Fried LP, Ferrucci L, Darer J, Williamson JD, Anderson G: Untangling the concepts of disability, frailty, and comorbidity: implications for improved targeting and care. J Gerontol A Biol Sci Med Sci 2004, 59:255-263.

3. Fried $L P$, Tangen $C M$, Walston J, Newman AB, Hirsch C, Gottdiener J, Seeman T, Tracy R, Kop WJ, Burke G, McBurnie MA, Cardiovascular Health Study Collaborative Research Group: Frailty in older adults: evidence for a phenotype. J Gerontol A Biol Sci Med Sci 2001, 56:146-156.

4. Rockwood K: Frailty and its definition: a worthy challenge. J Am Geriatr Soc 2005, 53:1069-1070.

5. Hogan DB, MacKnight C, Bergman H: Models, definitions, and criteria of frailty [review]. In steering comm, can Initiat frailty and aging. Aging Clin Exp Res 2003, 15(3 Suppl):1-29.

6. Sternberg SA, Schwartz AW, Karunananthan S, Bergman H, Clarfield M: The identification of frailty: a systematic literature review. J Am Geriatr Soc 2011, 59:2129-2138

7. Rockwood K, Mitnitski A: Frailty in relation to the accumulation of deficits. J Gerontol A Biol Sci Med Sci 2007, 62:722-727.

8. Speechley M, Tinetti M: Falls and injuries in frail and vigorous community elderly persons. J Am Geriatr Soc 1991, 39:46-52.

9. Mitnitski AB, Mogilner AJ, MacKnight C, Rockwood K: The mortality rate as a function of accumulated deficits in a frailty index. Mech Ageing Dev 2002, 123:1457-1460.

10. Rockwood K, Stadnyk K, Macknight C, McDowell I, Hebert R, Hogan DB: A brief clinical instrument to classify frailty in elderly people. Lancet 1999, 353:205-206.

11. Auyeung TW1, Lee JS, Kwok T, Woo J: Physical frailty predicts future cognitive decline - a four-year prospective study in 2737 cognitively normal older adults. J Nutr Health Aging 2011, 15:690-694.

12. Ávila-Funes JA, Helmer C, Amieva H, Barberger-Gateau P, Le Goff M, Ritchie K, Portet F, Carrière I, Tavernier B, Gutiérrez-Robledo LM, Dartigues JF: Frailty among community-dwelling elderly people in France: the three-city study. J Gerontol A Biol Sci Med Sci 2008, 63:1089-1096.

13. Jürschik $P$, Nunin $C$, Botiqué $T$, Escobar MA, Lavedán A, Viladrosa M: Prevalence of frailty and factors associated with frailty in the elderly population of Lleida, Spain: the FRALLE survey. Arch Gerontol Geriatr 2012, 55:625-631. 
14. Vermeulen J, Neyens JC, Van Rossum E, Spreeuwenberg MD, de Witte LP: Predicting ADL disability in community-dwelling elderly people using physical frailty indicators: a systematic review. BMC Geriatr 2001, 11:33.

15. Gill TM, Baker DI, Gottschalk M, Peduzzi PN, Allore H, Byers A: A program to prevent functional decline in physically frail, elderly persons who live at home. N Engl J Med 2002, 347:1068-1074.

16. Guralnik JM, Simonsick EM, Ferrucci L, Glynn RJ, Berkman LF, Blazer DG, Scherr PA, Wallace RB: A Short Physical Performance Battery assessing lower extremity function: Associated with self-reported disability and prediction of mortality and nursing home admission. J Gerontol, Ser A Med Sci Biol Sci 1994, 49:M85-M94.

17. Rantanen T, Guralnik JM, Foley D, Masaki K, Leveille S, Curb JD, White L: Midlife hand grip strength as a predictor of old age disability. JAMA 1999, 281:558-560.

18. Walston J, Fried LP: Frailty and the older man. Med Clin North Am 1999, 83:1173.

19. Janssen I, Baumgartner RN, Ross R, Rosenberg $\Vdash H$, Roubenoff R: Skeletal muscle cutpoints associated with elevated physical disability risk in older men and women. Am J Epidemiol 2004, 159:413.

20. Abellan Van Kan G, Rolland Y, Andrieu S, Bauer J, Beauchet O, Bonnefoy M, Cesari M, Donini LM, Gillette Guyonnet S, Inzitari M, Nourhashemi F, Onder G, Ritz P, Salva A, Visser M, Vellas B: Gait speed at usual pace as a predictor of adverse outcomes in community-dwelling older people an International Academy on Nutrition and Aging (IANA) Task Force. J Nutr Health Aging 2009, 13:881.

21. Cooper R, Kuh D, Hardy R: Objectively measured physical capability levels and mortality: systematic review and meta-analysis. BMJ 2010, 341:c4467.

22. Studenski S, Perera S, Patel K, Rosano C, Faulkner K, Inzitari M, Brach J, Chandler J, Cawthon P, Connor EB, Nevitt M, Visser M, Kritchevsky S, Badinelli S, Harris T, Newman AB, Cauley J, Ferruci L, Guralnik J: Gait speed and survival in older adults. JAMA 2011, 305:50

23. Robertson DA, Savva GM, Kenny RA: Frailty and cognitive impairment. A review of the evidence and causal mechanisms. Ageing Res Rev 2013, 12:840-851.

24. Kelaiditi E, Cesari M, Canevelli M, van Kan GA, Ousset PJ, Gillette-Guyonnet S, Ritz P, Duveau F, Soto ME, Provencher V, Nourhashemi F, Salvà A, Robert $P$, Andrieu S, Rolland Y, Touchon J, Fitten JL, Vellas B, IANA/IAGG: Cognitive frailty: rational and definition from an (I.A.N.A./I.A.G.G.) international consensus group. J Nutr Health Aging 2013, 17:726-734.

25. Buchner DM, Wagner EH: Preventing frail health. Clin Geriatr Med 1992, 8:1-17.

26. Ferrucci L, Guralnik JM, Studenski S, Fried LP, Cutler GB Jr, Walston JD: The Interventions on Frailty Working Group. Designing Randomized, Controlled Trials Aimed at Preventing or Delaying Functional Decline and Disability in Frail, Older Persons: A Consensus Report. J Am Geriatr Soc 2004, 52:625-634.

27. Tinetti ME, Baker DI, McAvay G, Claus EB, Garrett P, Gottschalk M, Koch ML Trainor K, Horwitz Rl: A multifactorial intervention to reduce the risk of falling among elderly people living in the community. N Engl J Med 1994, 331:821-827.

28. Gates S, Fisher JD, Cooke MW, Carter YH, Lamb SE: Multifactorial assessment and targeted intervention for preventing falls and injuries among older people in community and emergency care settings: systematic review and meta-analysis. Br Med J 2008, 336:130-133.

29. Fairhall N, Sherrington C, Kurrle SE, Lord SR, Lockwood K, Cameron ID: Effect of a multifactorial interdisciplinary intervention on mobility-related disability in frail older people: randomised controlled trial. BMC Med 2012, 10:120.

30. Barlow J: Building an evidence base for successful telecare implementation-updated report of the Evidence Working Group of the Telecare Policy Collaborative. London: Care Service Improvement Partnership. Health and Social Care. Change Agent Team. Department of Health; 2006.

31. Gillespie LD, Robertson MC, Gillespie WJ, Lamb SE, Gates S, Cumming RG, Rowe BH: Interventions for preventing falls in older people living in the community. Cochrane Database Syst Rev 2009, 2, CD007146.

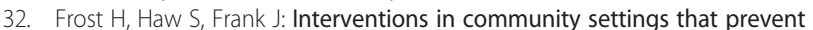
or delay disablement in later life: An overview of the evidence. Qual Ageing Older Adults 2012, 13:212-230.

33. Giné-Garriga $M$, Guerra M, Pagès $E$, Manini TD, Jiménez R, Unnihan VB: The effect of functional circuit training on physical frailty in frail older adults: a randomized controlled trial. J Aging Phys Act 2010, 18:401-424.
34. Brown M, Sinacore DR, Ehsani AA, Binder EF, Holloszy JO, Kohrt WM: Low intensity exercise as a modifier of physical frailty in older adults. Arch Phys Med Rehabil 2000, 81:960-965.

35. Thurston M, Green K: Adherence to exercise in later life: how can exercise on prescription programmes be made more effective? Health Promot Int 2004, 19:379-387.

36. Rolland Y, Dupuy C, Abellan van Kan G, Gillette S, Vellas B: Treatment strategies for sarcopenia and frailty. Med Clin N Am 2011, 95:427-438.

37. Morley JE, Argiles JM, Evans WJ, Bhasin S, Cella D, Deutz NE, Doehner W, Fearon KC, Ferruci L, Hellerstein MK, Kalantar-Zadeh K, Lochs H, MacDonald N, Mulligan K, Muscaritoli M, Ponikowski P, Posthauer ME, Rossi F, Schambelan M, Schols AM, Schuster MW, Anker SD, Society for Sarcopenia, Cachexia, and Wasting Desease: Nutritional recommendations for the management of sarcopenia. J Am Med Dir Assoc 2010, 11:391.

38. Evans WJ: Protein nutrition, exercise and aging. J Am Coll Nutr 2004, 23(6 Suppl):601-609.

39. Zoltick ES, Sahni S, McLean RR, Quach L, Casey VA, Hannan MT: Dietary protein intake and subsequent falls in older men and women: the framingham study. J Nutr Health Aging 2011, 15:147-152.

40. Tieland M, van de Rest O, Dirks ML, van der Zwaluw N, Mensink M, van Loon LJ, de Groot LC: Protein supplementation improves physical performance in frail elderly people: A randomized, double-blind, placebo-controlled trial. J Am Med Dir Assoc 2012, 13:720-726.

41. McDougall G, Becker H, Pituch K, Acee T, Vaughan P, Delville C: The SeniorWise study: Improving everyday memory in older adults. Arch Psychiatr Nurs 2010, 24:291-306.

42. Rebok GW, Langbaum JB, Jones RN, Gross AL, Parisi JM, Spira AP, Kueider AM, Petras H, Brandt J: Memory training in the ACTIVE study: how much is needed and who benefits? J Aging Health 2013, 25(Suppl 8):21-42.

43. Langlois F, Vu TT, Chassé K, Dupuis G, Kergoat MJ, Bherer L: Benefits of physical exercise training on cognition and quality of life in frail older adults. J Gerontol B Psychol Sci Soc Sci 2013, 68:400-404.

44. Baker L, Frank L, Foster-Schubert K, Green PS, Wilkinson CW, McTiernan A, Plymate SR, Fishel MA, Watson GS, Cholerton BA, Duncan GE, Mehta PD, Craft S: Effects of Aerobic Exercise on Mild Cognitive Impairment. A controlled trial. Arch Neurol 2010, 67:71-79.

45. Barnes DE, Santos-Modesitt W, Poelke G, Kramer AF, Castro C, Middleton LE, Yaffe K: The Mental Activity and eXercise (MAX) Trial: A randomized controlled trial to enhance cognitive function in older adults. JAMA Intern Med 2013, 173:797-804.

46. Chiatti C, Bustacchini S, Furneri G, Mantovani L, Cristiani M, Misuraca C, Lattanzio F: The economic burden of inappropriate drug prescribing, lack of adherence and compliance, adverse drug events in older people: a systematic review. Drug Saf 2012, 35(Suppl 1):73-87.

47. Jyrkkä J, Enlund H, Korhonen MJ, Sulkava R, Hartikainen S: Polypharmacy status as an indicator of mortality in an elderly population. Drugs Aging 2009, 26:1039-1048.

48. Clyne B, Bradley MC, Smith SM, Hughes CM, Motterlini N, Clear D, McDonnell R, Williams D, Fahey T, OPTI-SCRIPT Study Team: Effectiveness of medicines review with web-based pharmaceutical treatment algorithms in reducing potentially inappropriate prescribing in older people in primary care: a cluster randomized trial (OPTI-SCRIPT study protocol). Trials 2013, 14:72.

49. Perera S, Mody SH, Woodman RC, Studenski SA: Meaningful change and responsiveness in common physical performance measures in older adults. J Am Geriatr Soc 2006, 54:743-749.

50. Kwon S, Perera S, Pahor M, Katula JA, King AC, Groessl EJ, Studenski SA: What is a meaningful change in physical performance? Findings from a clinical trial in older adults (the LIFE-P study). J Nutr Health Aging 2009, 13:538-544.

51. Barber $\mathrm{JH}$, Wallis $J \mathrm{~B}, \mathrm{McKecting} \mathrm{E}$ : A postal screening questionnaire in preventive geriatric care. J Coll Gen Pract 1980, 30:49-51.

52. Lobo A, Saz P, Marcos G, Día JL, de la Cámara C, Ventura T, Morales Asín F, Fernando Pascual L, Montañés JA, Aznar S: Revalidation and standardization of the cognition mini-exam (first Spanish version of the Mini-Mental Status Examination) in the general geriatric population. Med Clin (Barc) 1999, 112:767-774.

53. Craig $C L$, Marshall AL, Sjostrom M, Bauman AE, Booth ML, Ainsworth BE, Pratt M, Ekelund U, Yngve A, Sallis JF, Oja P: International Physical Activity Questionnaire: 12-country reliability and validity. Med Sci Sports Exerc 2003, 35:1381-1389 [http://www.ipaq.ki.se/ipaq.htm] 
54. Lawton MP, Brody EM: Assessment of older people: self-maintaining and instrumental activities of daily living. Gerontologist 1969, 9:179-186.

55. Mahoney Fl, Barthel DW: Functional evaluation: The Barthel Index. Md State Med J 1965, 4:61-65.

56. Guigoz Y, Vellas B, Garry P: Assessing the nutritional status of the elderly: the Mini Nutritional Assessment as part of the geriatric evaluation. Nutr Rev 1996, 54(Suppl 2):59-65.

57. Peña-Casanova J, Guardia J, Bertran-Serra I, Manero RM, Jarne A: Shortened version of the Barcelona test (I): subtest and normal profiles. Neurologia 1997, 12:99-111.

58. Ware JE, Kosinski M, Keller SD: A 12-Item Short Form Health Survey. Construction of scales and preliminaty tests of reliability and Validity. Med Care 1996, 34:220-233.

59. Charlson M, Szatrowski TP, Peterson J, Gold J: Validation of a combined comorbidity index. J Clin Epidemiol 1994, 47:1245-1251.

60. Gallagher P, Ryan C, Byrne S, Kennedy J, O'Mahony D: STOPP (Screening Tool of Older Persons' Prescriptions) and START (Screening Tool to Alert Doctors to Right Treatment): consensus validation. Int I Clin Pharm Ther 2008, 46:72-83.

61. Fiatarone MA, O'Neill EF, Ryan ND, Clements KM, Solares GR, Nelson ME, Roberts SB, Kehayias JJ, Lipsitz LA, Evans WJ: Exercise training and nutritional supplementation for physical frailty in very elderly people. N Engl J Med 1994, 330:1769-1775.

doi:10.1186/1471-2318-14-125

Cite this article as: Romera et al:: Effectiveness of a primary care based multifactorial intervention to improve frailty parameters in the elderly: a randomised clinical trial: rationale and study design. BMC Geriatrics 2014 14:125.

\section{Submit your next manuscript to BioMed Central and take full advantage of:}

- Convenient online submission

- Thorough peer review

- No space constraints or color figure charges

- Immediate publication on acceptance

- Inclusion in PubMed, CAS, Scopus and Google Scholar

- Research which is freely available for redistribution 